\title{
Formação socioemocional: olhares para a docência na educação básica
}

\author{
Social and emotion training: looking at teaching in elementary education
}

Formación socioemocional: mirando a la enseñanza en educación primaria

\author{
Ezir George Silva ${ }^{1}$ \\ Thayanne Lima da Silva ${ }^{2}$
}

\begin{abstract}
Resumo
A partir da década de 1990, iniciou-se um movimento mundial na Educação marcado por reflexões sobre a escola desejada para o século XXI, trazendo à tona, por meio de diferentes documentos, a importância de uma perspectiva ampla do desenvolvimento humano, que incluísse, intencionalmente, aspectos socioemocionais. Essas reflexões impactaram na elaboração de legislações educacionais brasileiras, como a Lei de Diretrizes e Bases para Educação Básica (LDB) e, mais recentemente, a Base Nacional Comum Curricular (BNCC). Os achados apresentados têm como objetivo analisar os olhares para a formação socioemocional da docência na Educação Básica a partir da LDB e da BNCC. Em um segundo momento, propõe-se pensar sobre seus modos de aplicação e viabilidade para a prática docente e sua relação com os pressupostos que orientam a produção de currículo e seus conteúdos. Por fim, pretende-se chamar a atenção para a importância da formação humana e seus desdobramentos para as leituras acerca da relação do socioemocional com o político e o social. A pesquisa é de caráter documental e toma por base as legislações que regem a Educação Básica e suas propostas afins. Embora os aspectos socioemocionais sejam considerados desde a década de 1990 e tenham sido atualizados de lá para cá, ainda representa um grande desafio para a Educação pensar em uma formação docente e vivência da prática em um cenário cada vez mais globalizado, plural, tecnológico e, agora, pandêmico.
\end{abstract}

Palavras-chave: formação; socioemocional; docência; educação básica.

\begin{abstract}
From the 1990s onwards, it has began a worldwide movement in Education, marked by reflections about the desired school for the 21st century, highlighting through different documents the importance of a broad perspective of human development, which included intentionally social and emotional aspects. These reflections influenced brazilian educational laws, such as the Lei de Diretrizes e Bases para Educação Básica (LDB) and more recently the Base Nacional Comum Curricular (BNCC). This study aims to analyze the views on the social and emotional training of teaching in basic education based on the LDB and the BNCC. In a second step, it is proposed to think about its modes of application and feasibility for teaching practice and its relationship with the assumptions that guide the production of the curriculum and its contents. Also, it is intended to draw attention to the importance of human formation and its consequences for the readings about the link between social and emotional with the political and the social. This paper is document analysis based on the laws that

\footnotetext{
${ }^{1}$ Professor doutor, Universidade Federal Rural de Pernambuco, Centro de Educação, Departamento de Educação. Recife, PE, Brasil. E-mail: ezo.silva@ hotmail.com. ORCID: https://orcid.org/0000-0002-4289-073X

${ }^{2}$ Mestranda, Universidade Federal de Pernambuco, Centro de Educação, Departamento de Educação. Campina Grande, PB, Brasil. E-mail: <thayanne.lds@gmail.com>. ORCID: https://orcid.org/0000-0001-7159-3577
} 
govern basic education and its related proposals. Although social and emotional aspects have been considered since the 1990s and have been updated since then, it still represents a great challenge for Education to think about teacher training and experience of practice in an increasingly globalized, plural, technological and pandemic scenario.

Keywords: training; social and emotional learning; teaching; elementary education

\section{Resumen}

A partir de la década de 1990 se inició un movimiento mundial en Educación, marcado por reflexiones sobre la escuela deseada para el siglo XXI, destacando a través de diferentes documentos la importancia de una perspectiva amplia del desarrollo humano, que incluyera intencionalmente aspectos socioemocionales. Estas reflexiones se han visto afectadas por la redacción de las leyes educativas brasileñas, como la Ley de Diretrizes e Bases para Educação Básica (LDB) y más recientemente la Base Nacional Comum Curricular (BNCC). Este estudio tiene como objetivo analizar las visiones sobre la formación socioemocional de la docencia en educación básica a partir de la LDB y la BNCC. En un segundo paso, se propone reflexionar sobre sus modos de aplicación y factibilidad para la práctica docente y su relación con los supuestos que orientan la producción del currículo y sus contenidos. Finalmente, se pretende llamar la atención sobre la importancia de la formación humana y sus consecuencias para las lecturas sobre la relación de lo social y afectivo con lo político y lo social. La investigación es una análisis documental de las leyes que rigen la educación básica y sus propuestas relacionadas. Si bien los aspectos sociales y emocionales se han considerado desde la década de 1990 y se han actualizado desde entonces, todavía representa un gran desafío para la Educación pensar en la formación y experiencia de la práctica docente en un cenario cada vez más globalizado, plural, tecnológico y pandémico.

Palabras clave: formación; socioemocional; profesorado; educación primaria

\section{Introdução}

O mundo em que vivemos está cada vez mais complexo e exigente em suas diferentes áreas de formação, entre tantas, é cada vez mais consensual a ideia de que a dimensão socioemocional ocupa um lugar fundamental no conjunto de suas elaborações. Temas como autoconhecimento, resiliência e cooperação nunca foram tão abordados em diferentes espaços, inclusive na Educação. Mas, ao mesmo tempo, encontramo-nos rodeados de dúvidas e incertezas sobre como lidar com esta temática tão importante que ainda carece de evidências no contexto educativo brasileiro para se consolidar de forma viável e segura.

No âmbito do universo escolar, o diálogo sobre aspectos socioemocionais começou a ser abordado de forma mais intensa a partir da década de 1990, quando iniciou-se um movimento mundial marcado por diálogos que propuseram uma reflexão sobre a escola 
desejada para o século XXI (ABED, 2016), tendo como um dos principais marcos a publicação do relatório Educação: um tesouro a descobrir (DELORS, 2010), que constituiu uma reflexão crítica sobre a educação desejada e necessária para o século atual, privilegiando conhecimentos já previstos em uma perspectiva mais ativa de ensino somadas a habilidades de convivência e desenvolvimento de diferentes potencialidades; e a publicação do livro de Edgar Morin (2011) sobre aprendizados necessários à educação do futuro, fundamentados no paradigma da complexidade. Ambos os documentos retomam e enfatizam a importância do desenvolvimento integral discente, incluindo aspectos socioemocionais, modificando permanentemente paradigmas existentes na formação escolar até o final do século XX.

Esses documentos internacionais, dentre outros fatores, impactaram na elaboração de políticas brasileiras que fossem capazes de considerar diferentes dimensões do desenvolvimento humano no período escolar, como a Lei de Diretrizes e Bases para Educação Básica (LDB) e, mais recentemente, a Base Nacional Comum Curricular (BNCC). Ainda assim, considera-se um grande desafio para educação pensar em uma formação docente que tenha em sua base a formação socioemocional de quem educa.

Os educadores são os principais agentes do processo de formação socioemocional na educação básica. Desta forma, promover o desenvolvimento desses conhecimentos e habilidades nestes profissionais pode contribuir com o desenvolvimento de competências socioemocionais em alunos (ALZINA, 2015), além de auxiliar nos desafios que integram a profissão e a vida desse profissional (PACHECO; BERROCAL, 2015; MARQUES; TANAKA; FÓZ, 2019).

Ao levarmos em consideração este contexto, o presente artigo pretende analisar os olhares para a formação socioemocional da docência na Educação Básica a partir da LDB e da BNCC. Em um segundo momento, propõe-se pensar sobre seus modos de aplicação e viabilidade para a prática docente e sua relação com os pressupostos que orientam a produção de currículo e seus conteúdos. Por fim, pretende-se chamar a atenção para a importância da formação humana e seus desdobramentos para as leituras acerca da relação do socioemocional com o político e o social.

Do ponto de vista metodológico, a pesquisa é de caráter documental, caracterizada pela indicação de caminhos exploratórios e esclarecimentos de documentos a fim de produzir novos conhecimentos e outras perspectivas de compreensão (CECHINEL ET AL, 2016). Os materiais analisados foram a LDB (1996), os PCN's (BRASIL, 1997; 2000; 2006) e a BNCC 


\section{OD DEVIR EDUCAÇÃO \\ ISSN: 2526-849X}

(BRASIL, 2017), isto é, os principais documentos que regem a Educação Básica brasileira. Eles foram lidos e examinados conforme o objetivo do estudo e os resultados encontrados, assim como a discussão, encontram-se descritos a seguir.

\section{Lei de Diretrizes e Bases da Educação Nacional (LDB): perspectivas da integralidade}

Embora as discussões sobre uma educação efetivamente integral tenham se tornado mais intensas a partir da década de 1990 a nível de legislação, o Brasil já enfatizava em sua Constituição Federal de 1988, no Artigo 205 (BRASIL, 1988), a educação com foco no pleno desenvolvimento da pessoa, visando seu preparo para exercício da cidadania e sua qualificação para o trabalho.

Dentro de uma perspectiva de formação integral, um importante elemento surgiu na educação tradicionalmente tecnicista e pragmática: a extrapolação do aprendizado cognitivo para contemplação de outros aspectos do desenvolvimento. Esse âmbito formativo foi endossado em vários trechos da Lei de Diretrizes e Bases da Educação Nacional (LDB), publicada em 1996, quando propôs que os conteúdos curriculares da educação básica deveriam difundir "valores fundamentais ao interesse social, aos direitos e deveres dos cidadãos, de respeito ao bem comum e à ordem democrática" (BRASIL, 1996, s.p.). A lei incluía também uma formação que considerasse atitudes e valores (Idem, 1996, Art. 32); preparação para o trabalho e cidadania, "de modo a ser capaz de se adaptar com flexibilidade a novas condições de ocupação ou aperfeiçoamento posteriores” (Idem, 1996, Art. 35, s.p.); e a formação do educando enquanto pessoa humana, "incluindo a formação ética e o desenvolvimento da autonomia intelectual e do pensamento crítico" (Ibidem, 1996, Art. 35, s.p).

Após as proposições da LDB, foram publicados os Parâmetros Curriculares Nacionais (PCN's) (BRASIL, 1997), divulgados pelo Ministério da Educação e Cultura (MEC). Na base deste documento, pretendeu-se oferecer recursos para uma reorganização do ensino fundamental, a fim de auxiliar o professor em sua prática educativa de forma a ser referência para qualidade da educação em todo o país. 
Em sua introdução, ele sugere diretamente uma mudança de foco em relação aos conteúdos previstos no currículo, passando a considerá-lo um meio, ao contrário de um fim, para que os discentes pudessem desenvolver suas capacidades, além de criar e usufruir de bens culturais, sociais e econômicos. Nele, ficou estabelecido que:

O projeto educacional expresso nos Parâmetros Curriculares Nacionais demanda uma reflexão sobre a seleção de conteúdos, como também exige uma ressignificação, em que a noção de conteúdo escolar se amplia para além de fatos e conceitos, passando a incluir procedimentos, valores, normas e atitudes. Ao tomar como objeto de aprendizagem escolar conteúdos de diferentes naturezas, reafirma-se a responsabilidade da escola com a formação ampla do aluno e a necessidade de intervenções conscientes e planejadas nessa direção. (BRASIL, 1997, p. 48).

Dessa forma, ele divide os conteúdos em três categorias: conceituais, relacionados a fatos e princípios; procedimentais, relacionados a ações ordenadas e intencionais para atingir um determinado objetivo, partindo do propósito fundamental da educação; e atitudinais, que dizem respeito a valores, normas e atitudes.

Sobre esta última categoria, acrescenta-se:

É sabido que a aprendizagem de valores e atitudes é de natureza complexa e pouco explorada do ponto de vista pedagógico. Muitas pesquisas apontam para a importância da informação como fator de transformação de valores e atitudes; sem dúvida, a informação é necessária, mas não é suficiente. Para a aprendizagem de atitudes é necessária uma prática constante, coerente e sistemática, em que valores e atitudes almejados sejam expressos no relacionamento entre as pessoas e na escolha dos assuntos a serem tratados. Além das questões de ordem emocional, tem relevância no aprendizado dos conteúdos atitudinais o fato de cada aluno pertencer a um grupo social, com seus próprios valores e atitudes. Embora esteja sempre presente nos conteúdos específicos que são ensinados, os conteúdos atitudinais não têm sido formalmente reconhecidos como tal. A análise dos conteúdos, à luz dessa dimensão, exige uma tomada de decisão consciente e eticamente comprometida, interferindo diretamente no esclarecimento do papel da escola na formação do cidadão. (BRASIL, 1997, p. 50). 


\section{OO DEVIR EDUCAÇÃO}

ISSN: 2526-849X

Pode-se observar neste trecho uma consideração explícita sobre a aprendizagem socioemocional, embora ele ressalte posteriormente que tanto as categorias procedimentais como atitudinais não devem ser motivo para uma sobrecarga de conteúdo a ser trabalhado na escola, nem mesmo devem ser tratados como uma atividade específica. A proposta é que eles estejam presentes no cotidiano da sala de aula, como já acontece naturalmente, mas de maneira mais explícita, intencional e consciente.

Ainda nos PCN's, é abordado que aspectos emocionais e afetivos são tão relevantes quanto os cognitivos, especialmente em relação a alunos prejudicados por fracassos escolares ou que não estejam interessados no que a escola pode oferecer. Ele ainda cita a disponibilidade emocional dos alunos, dentre outros elementos, como fator essencial para uma aprendizagem significativa e melhoria da convivência em grupo, e ressalta a influência afetiva, emocional, cognitiva, física e de relação pessoal como parte da prática educativa.

Em uma das seções do documento citado, em que são apontados tópicos sobre didática, foram encontradas também menções a temas como ansiedade intensa, autoconceito, confiança, clima favorável, respeito mútuo e questões de ordem afetiva, indicando não apenas a complexidade da prática docente como também uma perspectiva integral que contempla a dimensão socioemocional como parte dessa prática.

Em 2000, foi publicada a versão dos PCN's para o ensino médio, reiterando a importância de fornecer uma educação que contribuísse para formação individual da pessoa, desenvolvimento de valores e competências de forma contextualizada com a sociedade, além de prever o "o aprimoramento do educando como pessoa humana, incluindo a formação ética e o desenvolvimento da autonomia intelectual e do pensamento crítico" (BRASIL, 2000, p. $10)$.

O referido documento enfatiza o desafio de integrar no processo educativo a dimensão cognitiva às demais dimensões, como a emocional, e estimula uma escola movida pela estética da sensibilidade, pautada na criatividade, curiosidade, inventividade e afetividade. Um dos pressupostos pelo qual o ensino médio deveria ser orientado, de acordo com os PCN's, é o "reconhecimento de que a aprendizagem mobiliza afetos, emoções e relações com seus pares, além das cognições e habilidades intelectuais" (BRASIL, 2000, p. 74).

Em 2006, na mesma direção dos outros documentos que propuseram orientar a educação no Brasil, a publicação dos Parâmetros Nacionais de Qualidade para a Educação Infantil (BRASIL, 2006) também levou em consideração um desenvolvimento integral que 
pudesse contemplar os aspectos físicos, psicológicos, intelectuais e sociais da criança, além de pontuar a inviabilidade de dissociar as dimensões cognitivas e afetivas do processo de interação.

O diálogo sobre a construção de uma concepção integral da educação que considerasse também a dimensão socioemocional cresceu durante o início do século XXI, sendo reforçada pelas Diretrizes Curriculares Nacionais para a Educação Básica (BRASIL, 2013), que enfatiza o respeito aos tempos mentais, socioemocionais, culturais e identitários dos estudantes como orientador de toda ação pedagógica, e foi melhor estruturada e sistematizada com a publicação final da Base Nacional Comum Curricular, em 2017.

\section{Base Nacional Comum Curricular (BNCC): outros olhares para a formação humana}

Em 2017, a BNCC, elaborada em cumprimento a exigência prevista na LDB (BRASIL, 1996), foi homologada em sua versão final, com a proposta de, enquanto documento normativo, garantir aprendizagens essenciais a todos os estudantes do país, bem como seu desenvolvimento integral por meio de dez competências gerais no decorrer da educação básica. Para além das críticas em relação a incoerências e inconsistências da BNCC (PERONI; CAETANO; ARELARO, 2019; SÜSSEKIND, 2019), o documento influencia não apenas a reorganização e elaboração de novos currículos, como a formação inicial e continuada dos docentes, elaboração de materiais didáticos, métodos avaliativos e exames nacionais (BRASIL, 2017; NEIRA; JÚNIOR; ALMEIDA, 2016).

Nela, fica estabelecido que:

A Educação Básica deve visar à formação e ao desenvolvimento humano global, o que implica compreender a complexidade e a não linearidade desse desenvolvimento, rompendo com visões reducionistas que privilegiam ou a dimensão intelectual (cognitiva) ou a dimensão afetiva. Significa, ainda, assumir uma visão plural, singular e integral da criança, do adolescente, do jovem e do adulto - considerando-os como sujeitos de aprendizagem - e promover uma educação voltada ao seu acolhimento, reconhecimento e desenvolvimento pleno, nas suas singularidades e diversidades. (BRASIL, 2017, p. 14). 
Nessa perspectiva, as aprendizagens propostas devem contribuir para assegurar aos estudantes o desenvolvimento de dez competências gerais que contemplam diferentes dimensões do humano, desde a valorização de elementos culturais e digitais a, novamente, aspectos socioemocionais, como autoconhecimento, reconhecimento de emoções, empatia, diálogo, responsabilidade, flexibilidade, resiliência, pensamento crítico e determinação.

Considerando que mudanças curriculares influenciam diretamente na formação não apenas de educandos, mas também de educadores e demais profissionais da educação básica, para além das relações de poder e interesses (NEIRA; JÚNIOR; ALMEIDA, 2016), considerou-se uma reflexão a partir do recorte das competências gerais que fazem menção ao aprendizado de habilidade socioemocionais. São elas:

6. Valorizar a diversidade de saberes e vivências culturais e apropriar-se de conhecimentos e experiências que lhe possibilitem entender as relações próprias do mundo do trabalho e fazer escolhas alinhadas ao exercício da cidadania e ao seu projeto de vida, com liberdade, autonomia, consciência crítica e responsabilidade.

7. Argumentar com base em fatos, dados e informações confiáveis, para formular, negociar e defender ideias, pontos de vista e decisões comuns que respeitem e promovam os direitos humanos, a consciência socioambiental e o consumo responsável em âmbito local, regional e global, com posicionamento ético em relação ao cuidado de si mesmo, dos outros e do planeta.

8. Conhecer-se, apreciar-se e cuidar de sua saúde física e emocional, compreendendo-se na diversidade humana e reconhecendo suas emoções e as dos outros, com autocrítica e capacidade para lidar com elas.

9. Exercitar a empatia, o diálogo, a resolução de conflitos e a cooperação, fazendo-se respeitar e promovendo o respeito ao outro e aos direitos humanos, com acolhimento e valorização da diversidade de indivíduos e de grupos sociais, seus saberes, identidades, culturas e potencialidades, sem preconceitos de qualquer natureza.

10. Agir pessoal e coletivamente com autonomia, responsabilidade, flexibilidade, resiliência e determinação, tomando decisões com base em princípios éticos, democráticos, inclusivos, sustentáveis e solidários. (BRASIL, 2017, p. 10)

Fica evidente, com a publicação da BNCC (BRASIL, 2017), a necessidade de considerar aspectos socioemocionais no processo de formação tanto do educando quanto do educador. Pode-se verificar na descrição das competências gerais supracitadas, o aprendizado 
de habilidades que permitam escolhas alinhadas ao projeto de vida, com liberdade, autonomia, consciência crítica e responsabilidade; posicionamento ético em relação ao cuidado de si mesmo e dos outros; cuidado com a saúde física e emocional, reconhecimento das próprias emoções e dos outros, autocrítica e capacidade de lidar com elas; empatia, diálogo, resolução de conflitos e cooperação; além de ações pessoais e coletivas autônomas, com responsabilidade, resiliência e determinação.

Nessa perspectiva, pode-se verificar um crescente diálogo sobre a integração de aspectos socioemocionais à formação humana dentro da educação básica desde a década de 1990. Ao mesmo tempo, também aumentam questionamentos como: "Quais seriam os principais desafios e possibilidades para uma formação docente que considere também o aprendizado de habilidades socioemocionais? Seria possível uma prática docente que contemple esta temática antes de um aprendizado prévio e introdutório que faça sentido na própria vida pessoal e profissional do educador? Quais contribuições uma formação socioemocional docente pode dar aos parâmetros e diretrizes educacionais brasileiros?". Estas perguntas orientam as reflexões a seguir, no âmbito de encontrar caminhos iniciais possíveis para as questões levantadas.

\section{Desafios e possibilidades para a formação socioemocional docente}

A BNCC é considerada um documento norteador também para elaboração e reorganização de políticas relacionadas a formação inicial e continuada docente, como a Base Nacional Comum Para a Formação Continuada de Professores da Educação Básica (BRASIL, 2020), que visa preparar de forma satisfatória este profissional para o exercício de sua profissão. Dessa forma, é inevitável não refletirmos sobre os desafios, que se desdobram também em possibilidades, relacionados a formação de quem educa, neste contexto específico, referente a aspectos socioemocionais.

Pesquisas na área de educação mostram que programas de educação socioemocional contribuem para o aprendizado de competências socioemocionais (WEISSBERG; GOREN; DOMITROVICH; DUSENBURY， 2013; ALZINA， 2015; MARQUES; PACHECO; BERROCAL, 2015; ARANTES, 2019; MARQUES; TANAKA; FÓZ, 2019) e promovem 


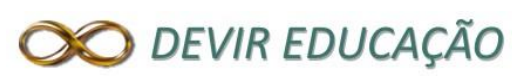

ISSN: 2526-849X

uma série de benefícios à vida individual e coletiva, apontando ser este um caminho promissor para o desenvolvimento socioemocional docente.

A educação socioemocional pode ser definida como um processo que visa a promoção e desenvolvimento de habilidades necessárias à vida, baseado no desenvolvimento de competências que envolvem reconhecer e lidar com as emoções de maneira saudável, estabelecer e manter relações interpessoais positivas, desenvolver responsabilidade para tomar decisões e gerenciar situações desafiadoras de forma construtiva e ética (WEISSBERG; GOREN; DOMITROVICH; DUSENBURY, 2013; CASTILLO-GUALDA ET AL, 2017; DURLAK; DOMITROVICH; WEISSBERG; GULLOTTA, 2015).

Os programas de educação socioemocional envolvem o desenvolvimento de habilidades relacionadas a inteligência emocional e habilidades sociais (CASTILLOGUALDA ET AL, 2017) e variam de acordo com a fundamentação e enfoque teórico. São vários os que buscam o desenvolvimento socioemocional em idade escolar (WEISSBERG; GOREN; DOMITROVICH; DUSENBURY, 2013; ALZINA, 2015; PACHECO; BERROCAL, 2015; BRACKET ET AL, 2016), no entanto, formações elaboradas e voltadas exclusivamente para o docente ainda são escassas (ARANTES, 2019; MARQUES; TANAKA; FÓZ, 2019).

Os educadores constituem os principais multiplicadores de uma formação socioemocional na educação básica, portanto, aprimorar e promover o desenvolvimento desses conhecimentos e habilidades neles pode, por consequência, contribuir com o desenvolvimento de competências socioemocionais em alunos (ALZINA, 2015), além de auxiliar nos desafios que integram a profissão e a vida desse profissional (PACHECO; BERROCAL, 2015; MARQUES; TANAKA; FÓZ, 2019).

Nos últimos anos tem crescido o interesse pelo desenvolvimento socioemocional do docente, compreendendo que esta área é fundamental ao seu crescimento (PACHECO E BERROCAL, 2015; PACHECO-SALAZAR, 2017; ALZINA, 2015; ARANTES, 2019; MARQUES; TANAKA; FÓZ, 2019) e ao cumprimento das legislações que são neste trabalho analisadas. Para além destes interesses, evidências apontam que a promoção de habilidades socioemocionais neste profissional pode ser considerada fator de proteção à sua saúde mental em sala de aula (FREIRE et al, 2012; ANDRADE; FRANCO, 2014; LEWIS, 2016; PACHECO-SALAZAR, 2017), além de estar relacionada a níveis mais baixos de atitudes incoerentes e distantes direcionadas aos alunos (PACHECO; BERROCAL, 2015), eficácia 


\section{OD DEVIR EDUCAÇÃO \\ ISSN: 2526-849X}

para lidar com situações desafiadoras em sala, motivação da aprendizagem, redução de comportamentos agressivos e condutas consideradas inapropriadas, além da promoção de um clima emocional positivo em sala de aula (CASASSUS, 2009; PACHECO; BERROCAL, 2015; ALZINA, 2015; MARQUES; TANAKA; FÓZ, 2019).

Apesar do crescente interesse na área, uma revisão integrativa de programas de intervenção para aprendizagem socioemocional do educador encontrou apenas 18 programas ao redor do mundo voltados exclusivamente para este profissional (MARQUES; TANAKA; FÓZ, 2019), a maioria dos programas desenvolvidos atualmente tem como foco principal os alunos.

Para Pacheco e Berrocal (2015), as habilidades socioemocionais do educador devem ser desenvolvidas no início da formação universitária e aprimoradas ao longo de formações continuadas. No entanto, sabemos que as Instituições de Ensino Brasileiras enfrentam desafios diante das transformações que ocorrem tanto em contextos imediatos como no mundo em geral (ABED, 2016), especialmente relacionadas aos processos que pretendem articular as práticas docentes às elaborações de propostas capazes de apontar para caminhos promissores.

\section{Considerações finais}

Conforme observado nas análises anteriores dos documentos oficiais que norteiam a Educação brasileira, pôde-se observar que embora os aspectos socioemocionais sejam considerados desde a década de 1990 e tenham sido atualizados de lá para cá, ainda representa um grande desafio para a Educação pensar em uma formação docente e vivência da prática em um cenário cada vez mais globalizado, plural, tecnológico e, agora, pandêmico.

Apesar de a formação socioemocional ser um caminho eficaz para o desenvolvimento pessoal e profissional docente e apresente uma série de benefícios comprovados, existem poucos estudos empíricos na academia brasileira (ARANTES, 2019; MARQUES; TANAKA; FÓZ, 2019) propondo a elaboração de propostas voltadas ao educador que consigam atender as exigências tanto dos documentos oficiais, que aqui foram discutidos, como dos desafios da realidade em que a prática docente tem sido vivenciada.

Revista Devir Educação, Lavras, vol.5, n.1, p.81-94, jan-jun/ 2021 
Diante disto, faz-se necessária a produção de novas pesquisas e a proposição de intervenções qualificadas que consigam tanto corresponder aos pressupostos da legislação educacional brasileira, quanto projetar outros olhares para as especificidades que envolvem a vivência e a prática do educador em uma perspectiva de cuidado humano deste profissional.

Ademais, considerando tanto o cenário nacional como outros estudos de nível internacional (SEE LEARNING, 2019; PACHECO; BERROCAL, 2015) torna-se indispensável uma adequação urgente aos princípios que orientam as formações inicial e continuada dos docentes que consigam corresponder às especificidades e desafios da Educação Básica no Brasil.

Por fim, parece-nos fundamental propor um conjunto de pesquisas, análises e outras intervenções que justifiquem e consolidem as contribuições da formação socioemocional para o desenvolvimento integral dos docentes, visando responder às lacunas da formação inicial, indicar outras categorias que consigam dialogar com as duras realidades do nosso tempo e com os desafios do homem no século XXI, viabilizando processos de formação que sejam humanos e humanizadores dos espaços educativos.

\section{Referências}

ABED, Anita Lilian Zuppo. O desenvolvimento das habilidades socioemocionais como caminho para a aprendizagem e o sucesso escolar de alunos da educação básica. Construção psicopedagógica, São Paulo, v. 24, n.25, p. 8-27, 2016. Disponível em: <http://pepsic.bvsalud.org/scielo.php?script=sci_arttext\&pid=S1415-69542016000100002>. Acesso em: 26 ago. 2020.

ALZINA, Rafael Bisquerra; GONZÁLEZ, Juan Carlos Pérez.; NAVARRO, Esther García. Inteligencia emocional en educación. 1 ed. Madrid: Sintesis, 2015.

ANDRADE, Cláudia; FRANCO, Glória. Inteligência emocional como fator protetor do burnout em Professores do $2 .^{\circ}$ e $3 .^{\circ}$ ciclos e secundário da RAM. International Journal of Developmental and Educational Psychology. INFAD. Revista de Psicología, v. 6, n. 1, p. 417-426, 2014. Disponível em: <https://www.redalyc.org/pdf/3498/349851790048.pdf> Acesso em: 26 ago. 2020

ARANTES, Mariana Marques. Educação emocional integral: análise de uma proposta formativa continuada de estudantes e professores em uma escola pública de Pernambuco. 
2019. 274 p. Tese (Doutorado em educação) - Universidade Federal de Pernambuco/ UFPE, Recife, 2019.

BRACKET, Marc et al. Emotional Intelligence. In Barrett, Lisa Feldman; Lewis, Michael; Haviland-Jones, Jeannette (Org.). Handbook of emotions. 4 ed. New York: Guilford Publications, 2016, 513-531.

BRASIL. Ministério da Educação. Base Nacional Comum Curricular: Educação é a Base. Brasília: MEC, 2017. 470 p. Disponível em:

http://basenacionalcomum.mec.gov.br/images/BNCC_20dez_site.pdf. Acesso em: 26 ago. 2020.

BRASIL. Constituição da República Federativa do Brasil. Congresso. Brasília, DF, 1988.

BRASIL. Lei de Diretrizes e Bases da Educação. Lei Federal n. o 9.394, de 26/12/1996.

BRASIL. Secretaria de Educação Fundamental. Parâmetros curriculares nacionais: introdução aos parâmetros curriculares nacionais / Secretaria de Educação Fundamental. - Brasília: MEC/SEF, p. 126, 1997.

BRASIL. Ministério da Educação. Parâmetros curriculares nacionais (ensino médio). Brasília: MEC/SEF, p. 109, 2000.

BRASIL. Ministério da Educação. Secretaria de Educação Básica. Parâmetros nacionais de qualidade para a educação infantil. Brasília: vol. 1, p. 64, 2006.

BRASIL. Ministério da Educação. Conselho Nacional de Educação. Conselho Pleno. Diretrizes Curriculares Nacionais para a Formação Continuada de Professores da Educação Básica. Projeto de Resolução CNE/CP. Brasília, 2020.

CASASSUS, Juan. Fundamentos da educação emocional. 1. ed. Brasília: Liber Livro; Unesco, 2009.

CASTILHO-GUALDA, Ruth et al. Resultados preliminares del método RULER en la inteligencia emocional y el compromisso laboral de profesores Españoles. Electronic Journal of Research in Educational Psychology, Espanha, v. 15, n. 3, p. 641-664. Disponível em: < http://ojs.ual.es/ojs/index.php/EJREP/article/view/1733> Acesso em: 15 jan. 2021

CHECHINEL, André. et al. Estudo/análise documental: uma revisão teórica e metodológica. Revista do programa de pós-graduação em educação - UNESC, Criciúma, v. 5, n. 1, 2016.

DURLAK, Joseph A. et al. (Org.). The handbook of social and emotional learning. 1 ed. New York: The Guilford Press, 2015.

FREIRE, Isabel et al. A Dimensão Emocional da Docência: Contributo para a Formação de Professores. Revista Portuguesa de Pedagogia, Portugal, v. 46, n. 2, p. 151-171, 2012. 
Disponível em: <https://impactum-journals.uc.pt/rppedagogia/article/view/1647-8614_462_8 > Acesso em: 15 jan. 2021

LEWIS, Michael. The emergence of humans emotions. In Barrett, L. F.; Lewis, M.; Haviland-Jones, Jeannette (Org.). Handbook of emotions. 4 ed. New York: Guilford Publications, 2016, 272-292.

MORIN, Edgar. Os sete saberes necessários à educação do futuro. 2. ed. São Paulo: Cortez; Unesco, 2011.

NEIRA, Marcos Garcia; JÚNIOR, Wilson Alviano; ALMEIDA, Déberson Ferreira de. A primeira e segunda versões da BNCC: construção, intenções e condicionantes. EccoS Revista Científica, São Paulo, v. 41, p. 31-44, 2016. Disponível em: https://www.redalyc.org/articulo.oa?id=71550055003. Acesso em: 12 jan. 2021.

PACHECO, Natalio Extremeta; BERROCAL, Pablo Fernandez. Inteligencia emocional y educación. 1 ed. Madrid: Editorial Grupo 5, 2015.

PACHECO-SALAZAR, Berenice Pacheco. Educación emocional en la formación docente: Clave para la mejora escolar. Ciencia y Sociedad, 42 (1): 104-110, 2017, DOI: 10.22206/cys.2017.v42i1.pp107-113.

DELORS, Jaques et al. (Org.). Um Tesouro a Descobrir: Relatório para a UNESCO da Comissão Internacional sobre Educação para o século XXI. Brasília: Unesco, 2010. Disponível em: <http://unesdoc.unesco.org/images/0010/001095/109590por.pdf>. Acesso em: 26 ago. 2020.

PERONI, Vera Maria Vidal; CAETANO, Maria Raquel; ARELARO, Lisete Regina Gomes. BNCC: disputa pela qualidade ou submissão da educação? Revista brasileira de política e administração da educação, São Paulo, v. 35, n. 1, p. 035 - 056, 2019. Disponível em: <https://seer.ufrgs.br/rbpae/article/view/93094> Acesso em: 15 jan. 2021

SEE LEARNING. Aprendizagem social, emocional \& ética. (Aprendizagem SEE). Livro de Apoio. Atlanta, GA: Universidade Emory, 2019.

SÜSSEKIND, Maria Luiza. A BNCC e o "novo" Ensino Médio: reformas arrogantes, indolentes e malévolas. Revista Retratos da Escola, Brasília, 13(25): 91-107, jan./mai., 2019. Disponível em: <http//www.esforce.org.br>. Acesso em: 12 jan. 2021.

MARQUES, Alcione Moreira; TANAKA, Luiza Hiromi; FÓZ, Adriana Queiróz Botelho. Avaliação de programas de intervenção para a aprendizagem socioemocional do professor: Uma revisão integrativa. Revista Portuguesa de Educação, v. 32, n. 1, p. 35-51, 2019. Disponível em: $\quad<$ http://www.scielo.mec.pt/scielo.php?script=sci_abstract\&pid=S087191872019000100004\&lng=pt\&nrm=iso > Acesso em: 07 jan. 2021

WEISSBERG, Roger et al. CASEL guide effective social and emotional learning programs: Preschool and elementary school edition. Chicago: CASEL, 2013. 